\title{
População em situação de rua: integrantes da classe trabalhadora?
}

\section{Homeless: Are they members of the working class?}

\author{
Verônica Martins Tiengo*
}

\begin{abstract}
Resumo: O artigo discute acerca da população em situação de rua, uma multifacetada expressão da questão social que demonstra a miséria provocada pelo modo de produção capitalista. Os que usam o trabalho informal como principal estratégia de sobrevivência são a maioria nas ruas. Foi feita uma pesquisa bibliográfica, com abordagem qualitativa, pautada sob o referencial crítico-dialético. O objetivo é entender por que e de que forma a população em situação de rua compõe ou não a classe trabalhadora. Este estudo argumenta sobre uma visão ampliada da classe trabalhadora, que abarca todos aqueles que vivem da venda de sua força de trabalho, e evidencia a atualidade da obra de Marx. Entende-se que a população em situação de rua integra a classe trabalhadora.
\end{abstract}

Palavras-chave: População em situação de rua; classe trabalhadora; trabalho.

\begin{abstract}
The article discusses the homeless, a multifaceted expression of the social question that demonstrates the misery caused by the capitalist mode of production. The majority of those who use informal work as their main survival strategy are in the streets. A bibliographic research was carried out, with a qualitative approach, based on the critical-dialectical theory. The objective is to understand why and how the homeless composes or not the working class. This study defends an enlarged vision of the working class, which embraces all those who live by the sale of their labour force, and, it highlights the relevance of Marx's work. It is understood that the homeless population is part of the working class.
\end{abstract}

Keywords: Homeless; working class; work.

Recebido em 26/12/2018. Aceito em 15/10/2020.

*Doutoranda do Programa de Pós-Graduação em Política Social da Universidade Federal do Espírito Santo (UFES); Mestra em Política Social (UFES); Bolsista FAPES no momento de elaboração do artigo; Assistente Social da Prefeitura Municipal de Vila Velha; Integrante do Núcleo de Estudos e Pesquisas da Situação de Rua (NESPSR); Pesquisadora vinculada ao Centro Brasileiro de Pesquisas Políticas e Sociais (CEBRApolis). E-mail: veronicatiengo@outlook.com.

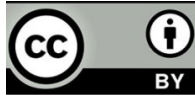

This content is licensed under a Creative Commons attribution-type BY 


\section{Introdução}

A expressão da questão social população em situação de rua, ainda que não seja nova, possui um grande diferencial no atual modo de produção: a combinação de acumulação de riqueza por alguns e "acumulação" de miséria por muitos. Em outras épocas, em modos de produção anteriores, existia fome, pobreza e pessoas vivendo nas ruas. Todavia a produção de riquezas em nada se aproximava daquela que o capitalismo produz.

Pensando no passado, o perfil da população em situação de rua era basicamente composto de pessoas com deficiência física e mental, crianças, viúvas e idosos. Hoje temos uma grande mudança, visto que, segundo as pesquisas, os que passam pelo processo de rualização são, em sua maioria, homens, em idade economicamente ativa e que nas ruas têm o trabalho informal como principal estratégia de sobrevivência ${ }^{1}$ (TIENGO, 2018a; PEREIRA, 2008; SILVA, 2009; BRASIL, 2008; CHILE, 2012).

Sabemos que a população em situação de rua sobrevive primordialmente pelo trabalho informal². Vejamos a citação seguinte:

Embora o fato de pessoas vivendo nas ruas, tradicionalmente concebidas como mendigos, andarilhos e "vadios", não seja um fenômeno específico dos dias de hoje, essa condição de vida adquire características próprias do momento atual. [...] Encontra-se hoje vítima do desemprego [...] incluído de forma perversa pela nossa sociedade, sobrevivendo do mercado informal e da assistência social que a cidade oferece e sem perspectivas de um futuro promissor (BORIN, 2004, p. 63, grifo nosso).

Há polêmica com relação ao entendimento de quem é a classe trabalhadora. Existem interpretações divergentes das obras de Marx. Enquanto alguns autores optam por uma visão ampliada da classe que depende da venda da força de trabalho para sobreviver, outros restringem a certos grupos aqueles trabalhadores do chão da fábrica, que diretamente criam mais-valia. Assim, com este trabalho discutimos sobre a composição da classe trabalhadora hoje. Objetivamos entender por que e de que forma a população em situação de rua compõe ou não a classe trabalhadora. O objeto deste artigo é a relação entre a população em situação de rua e a classe trabalhadora. Pautamos a discussão pelo referencial crítico-dialético, e o artigo origina-se de pesquisa bibliográfica com abordagem qualitativa.

Para a seleção das referências usadas para a elaboração deste artigo, fizemos um levantamento na Biblioteca Digital Brasileira de Teses e Dissertações (BDTD), na Scientific Electronic Library Online (SciELO), e nos periódicos da Capes, buscamos os temas "classe trabalhadora" e “população em situação de rua”. Na BDTD, para população em situação de rua encontramos 524 trabalhos, dos quais selecionamos 15, e para classe trabalhadora em Marx, 336, das quais duas foram selecionadas para a pesquisa. Nos periódicos da Capes, encontramos 152 sobre população em situação de rua, sendo oito relevantes, e 173 para classe trabalhadora em Marx, sendo um relevante. Na SciELO, encontramos 94 referências à população em situação de rua e 140 à classe trabalhadora em Marx, e os relevantes para a pesquisa foram respectivamente 10 e 16 . E, com base nessa seleção, ao lermos os textos, buscamos também os que foram citados por eles e nos pareceram relevantes.

${ }^{1}$ Com isso, não estamos afirmando que esses grupos que majoritariamente formavam a população em situação de rua não existem hoje, e sim que não representam a maioria.

${ }^{2}$ Ver mais em Tiengo (2020), Silva (2009), Rosa (2005), Chile (2012) e Brasil (2012). 
A busca foi feita entre agosto e setembro de 2018. Para a definição das referências selecionadas, foi feita a leitura de todos os títulos e resumos dos trabalhos. O critério de seleção foi apresentar o debate sobre a população em situação de rua ou sobre a classe trabalhadora. $O$ número total de referências encontradas foi alto, conforme vemos nos números apresentados, porém, quando abríamos os títulos e resumos, percebíamos que a maioria não trazia os nossos marcadores-chave como tema central ao debate.

Devemos estudar esse tema, pois é uma "expressão radical da questão social" (SILVA, 2009, p. 26) que necessita de um maior aprofundamento teórico. A população em situação de rua vem crescendo. Prova disso é o aumento dos serviços voltados para esse público. O Ministério de Desenvolvimento Social e Combate à Fome brasileiro noticiou em 2013 a ampliação desses serviços em todos os estados brasileiros. No que diz respeito a vagas de acolhimento, foram criadas 7.400. ${ }^{3}$

Cresceu também o número de estudos sobre o tema nas mais diversas áreas do conhecimento. Todavia ainda são poucos, quando comparamos a outros temas, aqueles pautados sob um referencial crítico. Almejamos que o artigo, além de contribuir com o acúmulo teórico sobre o assunto, sob um referencial crítico, possa ser útil ao movimento social da população em situação de rua e colaborar com a elaboração e o aperfeiçoamento das políticas públicas voltadas para o grupo que compõe a expressão da questão social que nos propomos a estudar. Esperamos também incentivar a luta contra a discriminação e atos de violência que penalizam a população em situação de rua.

0 processo de pesquisa envolve olhar, estranhar e fazer perguntas à realidade. Esse tema nos move a olhar dessa forma. Assim, pretendemos alcançar o objetivo não somente para escrever um trabalho, mas para melhor compreender e nos especializar sobre o assunto, bem como contribuir com o adensamento teórico, com a capacitação de gestores e técnicos e com a luta do movimento nacional de pessoas em situação de rua.

\section{População em situação de rua: quem é e como vive?}

O trabalho informal é uma das principais estratégias de sobrevivência da população em situação de rua. Segundo a pesquisa nacional brasileira sobre a população em situação de rua, somente $15,7 \%$ utilizam a mendicância como forma de sobrevivência, enquanto $70,9 \%$ usam o trabalho informal para sua subsistência. 0 trabalho informal, ao contrário de externo a relações capitalistas, serve ao capital, é funcional a ele. 0 capitalismo atingiu tal patamar de desenvolvimento que descobriu uma nova forma de ampliar a exploração do trabalhador: por meio do trabalho informal. "Dessa forma, o trabalho informal em vez de ser uma anomalia do sistema produtor de mercadorias é, na verdade, produto do capitalismo" (SOARES, 2008, p. 11).

Concomitantemente à diminuição dos postos de trabalho formais observada no período de crise econômica conjuntural das décadas de 80 e 90 no Brasil, os principais elementos condicionantes da intensificação do setor informal no contexto do mercado de trabalho têm origem nos processos de reestruturação produtiva [...]. Esses elementos conviveram com a internacionalização e expansão dos mercados financeiros, particularmente nos anos 90, com aprofundamento da internacionalização e expansão dos mercados (PAMPLONA et al., 2001, p. 59).

\footnotetext{
${ }^{3}$ Disponível em: http://www.brasilsemmiseria.gov.br/noticias/ultimas-noticias/2013/julho/atendimento-a-populacaoem-situacao-de-rua-sera-ampliado. Acesso em: 21 jul. 2015.
} 
Nesse contexto, houve ampliação da informalidade, que traz drásticas consequências para a classe trabalhadora, perdendo força de organização sindical e precarizando ainda mais as relações de trabalho. São trabalhos informais tanto aqueles mais pauperizados, voltados para a estrita sobrevivência, cuja renda aferida é baixa (como os desenvolvidos pela população em situação de rua), como também os trabalhos menos precarizados, com maiores rendas, em que os trabalhadores são pequenos empreendedores. O trabalho desenvolvido pela população em situação de rua encontra-se no nível mais pauperizado e instável possível (TAVARES, 2004).

Trabalho informal, portanto, se constitui numa estratégia funcional ao capital, especialmente nesta era de acumulação flexível, em que a diversidade de status de assalariados permite, com maior liberdade, uma exploração mais intensa dessa forma de trabalho (TAVARES, 2004, p. 48).

O trabalho informal, ao contrário de uma alternativa, possui "determinações imperativas do capitalismo" (SOARES, 2008, p. 44). É usado por pessoas que compõem a superpopulação relativa, um grupo externo ao exército ativo de trabalhadores, ou que a compõem de forma precária. Lembramos que a superpopulação relativa é condição de existência do capitalismo; assim, o fato de haver pessoas que não conseguem se inserir no mercado de trabalho não é fruto do acaso. Surge como consequência do modo de produção capitalista (MARX, 2013).

Marx (2013, p. 716) discute acerca da existência da superpopulação relativa, composta dos que estão "parcial ou inteiramente desocupados", divididos em três formas básicas (flutuante, latente, estagnada), e uma abaixo dessas (lumpemproletariado), que para nós também compõe a superpopulação relativa. Na heterogeneidade, que é marca fundamental da multifacetada expressão da questão social ${ }^{4}$ população em situação de rua, vemos a presença desse grupo populacional em todas as formas da superpopulação relativa. Logo, a população em situação de rua compõe a superpopulação relativa. Vejamos aqui a atualidade da obra de Marx. O que ele estudou dois séculos atrás ainda pode ser visto na realidade, e enquanto houver capitalismo suas reflexões serão válidas e imprescindíveis para estudos que transcendam a aparência e busquem uma totalidade (TIENGO, 2018b).

A acumulação de riqueza proporcional à "acumulação" de miséria é a expressão dessa Lei Geral. E a população em situação de rua demonstra com exatidão a "acumulação" de miséria nesse modo de produção. E, quando percebemos que a superpopulação relativa é tão fundamental ao capitalismo, que é considerado por Marx (2013) como uma alavanca, vemos que esse grupo populacional não se encontra nessa situação por desejo próprio, por sonharem viver na rua, e sim porque o capitalismo produz a superpopulação relativa, da qual eles fazem parte (TIENGO, 2018b).

Multifacetadas são as expressões da questão social envolvidas e os motivos relacionados ao processo de rualização5. Como afirma Silva (2009, p. 91), “constitui uma síntese de múltiplas determinações, cujas características, mesmo com variações históricas, o tornam um elemento de extraordinária relevância na composição da pobreza nas sociedades capitalistas".

\footnotetext{
${ }^{4}$ Entendemos a existência de pessoas que, sem alternativa, passam a viver em situação de rua como um fruto do capitalismo, um determinante da Lei Geral de Acumulação Capitalista. A população em situação de rua compõe a superpopulação relativa, em cada uma de suas formas. É uma expressão da questão social "especial”, pois traz em seu âmago uma gama diversa de outras expressões da questão social. Além da moradia nas ruas, que nos remete à ausência de uma habitação apropriada para moradia da humanidade, destacamos a pobreza, a fome, o desemprego e a drogadição. Ver mais em Tiengo (2020).
}

${ }^{5}$ Expressão usada por Prates, Prates e Machado (2011). 
Desabrigados, migrantes, indesejáveis, marginalizados, carentes, maltrapilhos, sem-teto, vagabundos, bandidos, maloqueiros, loucos, excluídos, trecheiros, desafortunados, mendigos, povo da rua, população de rua, moradores de rua e população em situação de rua; esses são alguns dos nomes para designar a expressão da questão social que nos propomos estudar. Diversos são os termos para determinar a vida nas ruas. De acordo com Rosa (2005, p. 65), "Trocam-se os termos mas não se trocam os comportamentos. E cada termo apresenta limitações à compreensão da diversidade de comportamentos e da heterogeneidade das situações".

Usamos o termo população em situação de rua por compreendermos que ele é o mais adequado para

[...] designar uma situação ou condição social que não resulta apenas de fatores subjetivos vinculados à sociedade e à condição humana, como é comumente considerada, mas é uma situação ou condição social produzida pela sociedade capitalista, no processo de acumulação do capital (SILVA, 2009, p. 29).

Muitos são os fatores que formam a multifacetada expressão da questão social população em situação de rua. Silva (2009, p. 105) divide-os em estruturais, biográficos e fatos da natureza. As causas estruturais "vinculam-se à estrutura da sociedade capitalista", e estão presentes a "ausência de moradia, a inexistência de trabalho e renda, as mudanças econômicas e institucionais de forte impacto social". Os biográficos estão ligados às trajetórias individuais. Aqui estão as "rupturas dos vínculos familiares, sofrimento psíquico, consumo frequente de álcool e drogas, infortúnios pessoais". E, nos fatos da natureza, destacam-se "terremotos, inundações etc.".

Um fator importante para o estudo da população em situação de rua é o fato de tratar-se de uma expressão da questão social majoritariamente urbana. Desde seu surgimento, está ligada às grandes cidades. Os grandes centros urbanos oferecem condições para a sobrevivência nas ruas. Sua arquitetura oferece locais propícios para pernoite, como embaixo de pontes e marquises. Também estão presentes as instituições como albergues e abrigos, a distribuição de comida por igrejas e a existência de possibilidade do trabalho informal, com latas e papelões espalhados pela rua, feiras nas quais podem trabalhar na montagem e desmontagem, caminhões que precisam de pessoas para carregá-los e descarregá-los. Vale destacar que, ainda que seja considerada uma expressão da questão social predominantemente urbana, há presença da população em situação de rua também nas cidades menores.

A população de rua se distingue entre uma minoria de grupos familiares que está na rua e, a maioria de "homens sós" que andam em grupos ou sozinhos, para os quais a família está "à distância” e é apenas uma referência (ESCOREL,1999, p. 17).

A população em situação de rua tem gênero, que é masculino. Ainda que existam mulheres em situação de rua, os homens são a maioria. Mesmo que na população brasileira o número de mulheres supere o de homens, e os homens morram mais do que mulheres em acidentes de trânsito e sendo vítimas da violência, como pode ser visto em dados do Instituto Brasileiro de Geografia e Estatística, nas ruas isso não ocorre (IBGE, 2020; IBGE, 2006). Uma explicação para isso é que as mulheres conseguem auxílio na família e inserção no emprego doméstico com maior facilidade do que os homens. O ideário popular de que o lugar das mulheres na sociedade patriarcal seja em casa contribui para serem a minoria nas ruas. Enquanto os homens são penalizados 
com a responsabilidade de serem os provedores, as mulheres carregam o papel de cuidadoras ${ }^{6}$ (VIEIRA; BEZERRA; ROSA, 2004).

Um dos fatores que contribuem para que eles sejam a maioria é a ideia do homem provedor, que motiva a busca de melhores condições de vida em outros locais, com a esperança de conseguir um emprego e proporcionar uma vida melhor para sua família. Na sociedade capitalista, cuja moral é patriarcal, é o homem quem deve manter economicamente sua família. É ele que deve sair, trabalhar e pagar as contas. ${ }^{7}$ Quando o homem perde o emprego, ele se sente envergonhado por não cumprir seu papel de provedor e, ao migrar em busca de melhores condições e não conseguir, prefere ficar em situação de rua a voltar para casa em condições piores do que saiu. Seguem dois exemplos que servem como ilustrações disso. Os relatos foram encontrados a partir de nossa pesquisa bibliográfica (VIEIRA; BEZERRA; ROSA, 2004; ESCOREL, 1999).

Miguel [...]: eu não posso voltar pra casa do jeito que eu tô, por isso eu queria arrumar um quarto pra mim, estabilizar-me de novo, ir juntando meu dinheiro, levar minha vida normal como eu tinha antigamente, depois, comprar minhas coisas como eu tinha e aí agarrar e voltar pra minha casa; vou chegar na minha casa de bermuda e uma mochila nas costas?

Cícero [...]: às vezes eu penso em voltar, sabe? Mas voltar da forma que eu tô não posso não... eu tenho a maior vergonha de voltar pra minha casa da forma que eu tô, destruído, tinha que tar melhor, sabe? ó só, vou falar uma coisa... sem dente, sem roupa, sem nada, sei lá, destruído totalmente, não volto não (ESCOREL, 1999, p. 147)

Vejamos que essas citações expressam vergonha em voltar para casa. Podemos ver que a ideologia dominante (que defende a individualização das expressões da questão social, como se os próprios sujeitos que passam pela rualização houvessem buscado essa situação) está presente, como se eles tivessem culpa de sua situação, de não conseguir corresponder ao papel que lhe foi imposto na sociedade. Outro ponto presente é a centralidade no trabalho, a busca do trabalho formal que lhe ofereça condições de romper com a rualização.

Apesar de entendermos a população em situação de rua como um grupo heterogêneo, percebemos trajetórias comuns. É frequente que a motivação da saída de casa seja a busca de melhores condições de vida, com a esperança de encontrar um bom trabalho no local para onde vão, e, quando não conseguem, eles sentem vergonha de voltar para casa e acabam ficando pelas ruas. Essa trajetória é ratificada por meio dos dados da pesquisa nacional, no que diz respeito aos fatores envolvidos na ida para as ruas, como pode ser visto no quadro que segue, juntamente com as principais características da população em situação de rua (ROSA, 2005; SILVA, 2009; TIENGO, 2020).

\footnotetext{
${ }^{6}$ Com o passar do tempo, as mulheres conquistaram uma série de direitos, e muitas conseguiram romper com o estereótipo da dona de casa responsável por todos os cuidados da casa e da família. Porém, ainda que muitos avanços tenham sido feitos, e de muitas serem totalmente responsáveis por suas famílias, ainda enfrentamos a presença desse pensamento retrógado, com o qual não concordamos, mas percebemos que a sua presença contribui para que o processo de rualização seja majoritariamente masculino. Ver mais em Tiene (2004).

${ }^{7}$ Vejamos que não estamos corroborando essa ideia. Somente dizemos o que aparece nos relatos de pessoas que vivem em situação de rua. Ainda que muitas mulheres sejam as principais provedoras de suas famílias, e apesar de todas as conquistas conseguidas, permanecem visões patriarcais.
} 
Quadro 1 - Características da população em situação de rua

\begin{tabular}{|c|c|}
\hline Perfil & Dados \\
\hline Sexo & $82 \%$ são homens. \\
\hline Idade & $53 \%$ entre 25 e 44 anos. \\
\hline Escolaridade & $63,5 \%$ não concluíram o Ensino Fundamental. \\
\hline Alimentação & 79,6\% conseguem realizar pelo menos uma refeição por dia. \\
\hline $\begin{array}{l}\text { Documentos de } \\
\text { identificação }\end{array}$ & $\begin{array}{l}\text { 21,9\% possuem todos os tipos listados (identidade, CPF, carteira de trabalho, } \\
\text { certidão de nascimento, título eleitoral). } \\
24,8 \% \text { não possuem nenhum tipo de documento. }\end{array}$ \\
\hline $\begin{array}{l}\text { Principais atividades } \\
\text { realizadas na rua }\end{array}$ & $\begin{array}{l}\text { Catação de materiais recicláveis }(27,5 \%) \\
\text { Lavar e vigiar carros }(14,1 \%) \text {, sendo que } 70,9 \% \text { estão envolvidos em } \\
\text { trabalhos informais, enquanto somente } 15,7 \% \text { pedem dinheiro ou } \\
\text { mendigam para sobreviver. }\end{array}$ \\
\hline Motivos da situação de rua & $\begin{array}{l}\text { 35,5\% relataram alcoolismo e/ou drogas; } \\
\text { 29,1\% apontaram desentendimentos familiares; } \\
\text { 29,8\% citaram o desemprego; } \\
\text { 20,4\% disseram falta de moradia; } \\
\text { 16,1\% relataram separação/decepção amorosa. }\end{array}$ \\
\hline Deslocamentos & $\begin{array}{l}\text { 54,2\% são migrantes. } \\
\text { Destes: } \\
\text { 60,1\% não estavam em situação de rua na cidade de onde vieram; } \\
\text { 45,3\% tiveram a migração motivada pela busca de trabalho; } \\
\text { 18,4\% migraram devido a desavenças familiares. }\end{array}$ \\
\hline Tempo de rua & $48,4 \%$ estão há mais de dois anos em situação de rua. \\
\hline Pernoite & $\begin{array}{l}\text { 69,6\% costumam dormir nas ruas; } \\
\text { 22,1\% utilizam albergues e outras instituições para pernoite; } \\
\text { 8,3\% alternam a rua e instituições. }\end{array}$ \\
\hline $\begin{array}{l}\text { Acesso a programas } \\
\text { governamentais }\end{array}$ & $\begin{array}{l}\text { 88,5\% não acessam nenhum tipo de benefício; } \\
\text { 3,2\% são aposentados; } \\
\text { 2,3\% recebem o benefício bolsa família; } \\
\text { 1,3\% acessa o benefício de prestação continuada. }\end{array}$ \\
\hline Movimentos sociais & 95,5\% não participam de nenhum movimento social. \\
\hline
\end{tabular}

Fonte: a autora com base em Brasil (2008)

Homens, em idade economicamente ativa, desempregados, com as relações familiares esgarçadas, baixo nível instrucional, que não possuem condições financeiras para manter uma moradia e, quando chegam à situação de rua, utilizam primordialmente o trabalho informal como estratégia de sobrevivência. Esse é o perfil da população em situação de rua (BRASIL, 2008; SILVA, 2009; ROSA, 2005; ESCOREL, 2006; VIEIRA; BEZERRA ; ROSA, 2004; SNOW; ANDERSON, 1998).

$\mathrm{O}$ álcool e outras drogas também estão presentes nas trajetórias desse grupo populacional. Entretanto nem sempre confluem como causa da ida para as ruas; podem ser também consequência. Dissemos que a principal marca da expressão da questão social aqui estudada é a heterogeneidade, dessa forma existem ambos os grupos: tanto pessoas que usavam álcool e drogas antes quanto aqueles que passam a utilizá-los como uma forma de esquecer os problemas, como um analgésico para sanar as dores provocadas pela condição a que chegaram (SILVA, 2009; VIEIRA; BEZERRA; ROSA, 2004). Segue um relato para ilustrar a discussão teórica feita até o momento: 
Wesley [...]. Pernambucano de trinta anos [...], completou o ensino fundamental, mas não conseguindo conciliar estudo e trabalho, parou de estudar [...]. Desde os onze anos trabalhava nas folgas do vigia do posto de gasolina e como auxiliar em loteria esportiva, até atingir a maioridade. [...] Em 1997, contando com a ajuda de uma irmã, comprou uma passagem para São Paulo [...]. Morava na rua desde que chegara. Não conseguiu trabalhar como motorista [...]. Às vezes costumava guardar barracas para os camelôs e catar latas [...]. Sentia vergonha por morar na rua e, frequentemente, no contato com a família, mentia (ROSA, 2005, p. 95, grifo nosso).

Lembramos que a fonte do relato é a nossa pesquisa bibliográfica. Vemos por meio do relato que Wesley trabalha desde muito cedo, não continuou estudando pela necessidade em trabalhar e queria conseguir um trabalho no Sudeste para ajudar a família. Encontramos alguns pontos importantes do processo de rualização. O primeiro é a questão da bebida alcoólica, um dos fatores que, associado a outros, compõem a multiplicidade presente na expressão da questão social aqui estudada, que nem sempre são usados antes da situação de rua, como no caso de Wesley. O segundo é a ideia do homem provedor. Percebemos isso quando ele diz que se sente inútil por não poder ajudar sua família.

Além disso, percebemos que sua vida gira em torno do trabalho. Ele migrou para o Rio de Janeiro. Enquanto estava empregado, ficou nesse local; porém, ao perder o trabalho, voltou para o Recife e mais tarde foi para São Paulo, onde passou pelo processo de rualização, ao não conseguir trabalho formal. Chamamos atenção para a estratégia de sobrevivência usada por ele: o trabalho informal. E uma das atividades citadas por ele, a catação de latas, está entre as principais utilizadas pela população em situação de rua segundo a pesquisa nacional, como pode ser observado no Quadro 1.

Borin (2004) pesquisou São Paulo e percebeu a centralidade do trabalho informal. Rosa (2005), que também estudou São Paulo, e Silva (2009), pesquisando Recife, Belo Horizonte, Porto Alegre e São Paulo, oferece indícios do mesmo fato, isto é, a importância do trabalho informal na vida das pessoas em situação de rua.

Rosa (2005) entende que as pessoas em situação de rua utilizam o trabalho informal como atividade, especialmente desde o final da década de 1970 no Brasil. A pesquisa nacional sobre a população em situação de rua indicou que grande parcela desse grupo populacional, mais de 70\%, tem o trabalho informal como forma de sobrevivência (BRASIL, 2008; ROSA, 2005).

Vieira, Bezerra e Rosa (2004), Rosa (2005), Silva (2009), Pereira (2008) e Tiengo (2020) argumentam que o grupo populacional que passou pelo processo de rualização não é formado basicamente por mendigos. Eles utilizam o trabalho como principal forma de sobrevivência. Quanto a isso, temos inteira concordância. De fato, percebemos como um grave erro chamá-los de mendigos, pois, além de ser degradante, desconsidera a situação de rua como uma expressão radical da questão social, com ampla ligação ao modo de produção capitalista, além do fato de a pesquisa nacional (BRASIL, 2008) indicar a minoria das pessoas em situação de rua: somente 15,7\% utilizam a mendicância como principal atividade.

A população em situação de rua faz parte da classe trabalhadora. Assim, mesmo em situação de rua, em sua maioria, não consegue adequar-se a outras formas de sobrevivência. O trabalho é fulcral em suas vidas e muitos envergonham-se de estratégias tais como o mangueio ${ }^{8}$, o pedido e

\footnotetext{
${ }^{8}$ Manguear é uma estratégia de sobrevivência de pessoas em situação de rua. Consiste em contar uma história triste de forma que comova as pessoas que passam pelas ruas a lhes ajudar. Normalmente as solicitações são em dinheiro (KUNZ, 2012).
} 
a mendicância. Segue um relato sobre a importância do trabalho na vida das pessoas em situação de rua, retirado de uma de nossas referências da pesquisa bibliográfica, em que é evidenciada uma reprodução ideológica:

“Trabalho é coisa linda, é tudo na vida." "Trabalho é essencial ao homem, para sentir-se bem em qualquer lugar." "Trabalho é independência, é ter direitos, é andar arrumado." "Trabalho é entrar na sociedade e não ser marginal." Por outro lado, a ideia de perda do trabalho é relacionada a perda de identidade, perda de condições de vida e autoestima: "não trabalhar é estar pesado, morto" (PORTO ALEGRE apud SILVA, 2009, p. 170).

Com essa citação, vemos as falas de pessoas em situação de rua sobre o trabalho. Vejamos que o trabalho, para além de suas condições objetivas de servir para a sobrevivência, possui conotação subjetiva. Quando eles dizem sobre a beleza do trabalho, isso remete a uma visão romântica do que seria esse trabalho. Lembramos que o trabalho em voga é aquele assalariado, aprisionado pelo capitalismo.

A centralidade da magnitude do trabalho é apresentada de forma evidente quando dizem que o trabalho é “tudo". Nesse contexto, se estão sem um trabalho, eles perderam tudo, estão sem nada, o que nos remete àquelas outras falas nas quais destacamos os motivos de não voltarem para casa, por estarem destituídos de tudo.

Assim, vemos que as características positivas, como ter independência, andar arrumado, ter direitos, são diretamente vinculadas ao trabalho. E esse trabalho é o formal, aquele em que ele terá uma carteira assinada e poderá acessar os direitos trabalhistas. Os pequenos serviços desenvolvidos em situação de rua nem sempre são considerados trabalhos, pois não carregam essa positividade aqui descrita; são um trabalho que lhes permite somente reproduzir as condições miseráveis em que vivem (TIENGO, 2020).

Agora que conhecemos quem é e como vive a população em situação de rua, estudaremos sobre a classe trabalhadora para discutirmos se a expressão da questão social aqui estudada compõe ou não a classe trabalhadora, e se sim, de que forma o faz.

\section{Classe trabalhadora: quem a compõe?}

A partir daqui, discutiremos sobre a classe trabalhadora. Esse tema envolve diversas discussões e abarca uma gama enorme de opiniões. Dessa forma, nosso objetivo não é esgotar o assunto, e sim trazer elementos importantes para a discussão. Neste item, pretendemos refletir sobre algumas perguntas, tais como: quem é a classe trabalhadora? Ela está restrita aos trabalhadores do chão da fábrica? A população em situação de rua faz parte da classe trabalhadora?

Bezerra (2013) apresenta três perspectivas no estudo da classe trabalhadora. São elas: 1) Contenção e/ou enrijecimento; 2) Ampliação; 3) Frouxa e/ou esquizofrênica. A primeira perspectiva pauta o debate pela herança marxista: "as transformações que ocorrem nos últimos anos são sempre 'problematizadas' de acordo com o entendimento do que Marx afirmava ser a classe trabalhadora", de acordo com a interpretação do autor (BEZERRA, 2013, p .41). Sérgio Lessa vê a classe trabalhadora como composta de proletários. Estes são para Lessa os que produzem a riqueza. Os seguidores dessas ideias dizem que o debate realizado por Marx não precisa de adições ou alterações. 
Para Bezerra (2013), é inegável que a obra de Marx seja imprescindível. Todavia a teoria marxista não é o bastante, então ele discorda dessa primeira perspectiva:

[...] devemos contestar o enrijecimento dos conceitos, inclusive o de classe social, tendo como enfoque a relação espaço - tempo da social, tendo como enfoque a relação da sociedade e os desdobramentos para o quadro social, político, cultural e econômico (BEZERRA, 2013, p. 44).

A segunda perspectiva, de ampliação, com a qual Bezerra (2013) concorda, busca o novo na discussão a respeito do trabalho e da classe trabalhadora, sob o contexto do século XXI, com diversas mudanças no mundo do trabalho (reestruturação produtiva, ampliação da precarização e da informalidade). Bezerra (2013) considera que Ricardo Antunes seja o exemplo dessa perspectiva. Os estudos nessa área envolvem além do setor de serviços:

[...] o desenvolvimento de novas tecnologias microeletrônicas e seu impacto gerado pelo desemprego e também a criação de novo tipo de trabalho na esfera dos impulsos à qualificação [...], estudos sobre os trabalhadores que vivem nas grandes metrópoles e suas estratégias de sobrevivência no universo de trabalho informal. No limite, busca-se cada vez mais entender aqueles trabalhadores que nas condições do capitalismo atual não conseguem sequer vender sua força de trabalho (BEZERRA, 2013, p. 46).

Os que seguem a terceira perspectiva tendem a abandonar o conceito de classe trabalhadora, visto que para eles isso não é importante, os pós-modernos compõe essa visão, eles questionam o conceito tradicional de proletariado (BEZERRA, 2013).

A reestruturação produtiva, associada às outras mudanças no mundo do trabalho, produziu "novas fragmentações no interior da classe e, consequentemente, novas identidades do trabalho estranhado, bem como atinge expressivos segmentos de trabalhadores vinculados às relações de produção não essencialmente capitalistas" (THOMAZ JÚNIOR, 2008, p. 124).

Thomaz Júnior (2008) considera que a classe trabalhadora teve o seu crescimento ampliado, e fazem parte dela os trabalhadores por conta própria, autônomos, operadores de telemarketing, digitalizadores, trabalhadores da cibernética, os terceirizados, subcontratados e trabalhadores informais.

A classe trabalhadora aumentou de tamanho e em quantidade, porém de forma heterogênea, fragmentada e crescentemente precarizada. Mais ainda, diferenciada pelos territórios e lugares, sobretudo nos países onde predominam os baixos índices de proteção social e de políticas sociais mais abrangentes (THOMAZ JÚNIOR, 2008, p. 125).

Marcel Van Der Linden (2005) considera o conceito da classe trabalhadora em Marx como limitada e propõe uma nova conceituação. Entretanto não vemos um caminho adequado para discutir a classe trabalhadora sem pautar o debate em Marx. Ainda que alguns autores discordem de sua análise, como o citado no início do parágrafo, seus argumentos não são suficientes para propor um novo conceito, que seria baseada em tipologias. Para ele, os trabalhadores, a quem chama de empregados, possuem meios de produção, e ele vê como erro dividir a sociedade entre burguesia e proletariado, o que fica claramente oposto ao que Marx (2013) debate. E não é possível discutir de forma aprofundada a classe trabalhadora sem o pilar da teoria marxista. 
Sérgio Lessa (2008) separa os trabalhadores assalariados dos proletários. Esses últimos produziriam a riqueza enquanto a burguesia e os trabalhadores assalariados se apropriariam do que foi produzido, e somente o operariado teria o poder revolucionário.

Sendo o trabalho operário a origem de todo "o conteúdo material da riqueza" (o que não quer dizer, como vimos, a única fonte de mais-valia) isto significa que todo o restante da sociedade vive da sua exploração. Ou seja, a única classe que vive do seu próprio trabalho é a classe operária. Por essa razão é ela a única classe para a qual a extinção da propriedade privada é condição para sua emancipação. Todas as outras classes vivem, direta ou indiretamente, da exploração do trabalho operário e têm, por isso, na propriedade privada dos meios de produção a condição primeira de sua existência (LESSA, 2008, p. 13).

Valência (2000) discorda de Lessa, pois, considerando os livros I, II e III de O Capital, a classe trabalhadora não é composta somente do operariado. Considera que o operariado seria o "núcleo duro" da classe trabalhadora, porém os trabalhadores presentes nos diversos ramos da produção e da circulação também fazem parte e formam o proletariado em seu sentido amplo.

E, ao contrário de Lessa, que vê o operariado como aqueles que produzem a riqueza material, os únicos que podem destruir a propriedade privada, Valência argumenta que só seria possível uma transição para uma nova sociedade quando associada ao operariado, sendo somadas "todas as classes exploradas da moderna sociedade burguesa de nossos dias" (VALÊNCIA, 2000, p. 12). Segundo Marini:

[...] restringir la classe obrera a los trabajadores asalariados que producen la riqueza material, es decir, el valor de uso sobre el que reposa el concepto de valor, corresponde a perder de vista el proceso global de la reproducción capitalista. Como lo destaca repetidamente Marx, el desarrollo de la producción mercantil capitalista no hace sino acrecentar el número de trabajadores asalariados $\mathrm{y}$, por tanto, de los obreros involucrados en el proceso de reproducción (MARINI, 2015, s/p).

Antunes $(2008$, p. 8) concebe a classe trabalhadora como composta para além dos trabalhadores que diretamente produzem a riqueza e abarca também a "totalidade do trabalho social e coletivo". E fazem parte desse grupo os trabalhadores informais e os desempregados e precarizados. "Desemprego ampliado, precarização exacerbada, rebaixamento salarial acentuado, perda crescente de direitos, esse é o desenho mais frequente da nossa classe trabalhadora" (ANTUNES, 2008, p. 6). Enfim, todos aqueles que vendem a sua força de trabalho trocando-a por salário compõem a classe trabalhadora, assim como os que não conseguem trocar, ou seja, os desempregados. Todos esses formam o que Antunes (2008) chama de a classe-que-vive-do-trabalho.

Para Marx (2003), a sociedade está dividida em duas grandes classes: a burguesia e o operariado. E o operariado é a única classe potencialmente revolucionária, capaz de destruir o modo de produção capitalista.

Na mesma proporção em que a burguesia, ou seja, o capital, se desenvolve, desenvolve-se também o proletariado, a classe dos trabalhadores modernos, que só podem viver se encontrarem trabalho, e só encontram trabalho na medida em que este aumenta o capital. Esses trabalhadores que são obrigados a vender-se diariamente, são uma mercadoria, um artigo de comércio, sujeitos, portanto, às vicissitudes da concorrência, às flutuações do mercado (MARX, 2003, p. 32, grifo nosso). 
O que podemos inferir dessa citação? Não somente nessa fala de Marx (2003), bem como em seu pensamento expresso em outros de seus textos, temos uma contradição básica vinculada ao modo de produção capitalista. Qual é? O fato de a burguesia depender do proletariado, visto que é o trabalho que gera a riqueza, logo sem a força de trabalho do proletariado não há criação de riquezas, e há exploração dessa fonte de riqueza. E, ainda que o trabalhador se empenhe para além dos limites de sua própria capacidade física, mesmo que ele não descanse o suficiente para repor o desgaste de sua força de trabalho nem tenha uma alimentação adequada, visto que o pagamento que recebe por sua força de trabalho nem sempre é suficiente para isso, o seu esforço promove diretamente o enriquecimento alheio, daqueles que possuem os meios de trabalho. 0 proletariado só pode sobreviver se vender a sua força de trabalho, e, uma vez que a sua existência depende disso, ele não tem outra mercadoria. Sendo assim, vender sua força de trabalho é como se vendesse a si mesmo como mercadoria para servir ao capital.

Outro ponto importante da citação é revelar quem é a classe trabalhadora, aqueles que só têm a força de trabalho para vender no mercado de coisas e que precisam trocá-la para adquirir condições de sobrevivência. A hipótese é a de que a classe operária que é potencialmente revolucionária, ao contrário do que Lessa argumenta. E, de acordo com o pensamento de Antunes (2008) e Marini (2015), não se restringe ao operariado industrial, que produz a riqueza material, pois, além desses, estão presentes todos aqueles que só possuem a força de trabalho para trocar no mundo da mercadoria, e faz parte desses a população em situação de rua.

Marx (2003) alega que em todas as sociedades houve antagonismos entre classes, e uma explorava a outra. Porém, para que a exploração ocorresse, era imprescindível que fossem oferecidas condições suficientes para que os explorados continuassem vivos. Entretanto no capitalismo ocorre algo diferente:

O operário moderno, ao contrário, em vez de elevar sua posição com o progresso da indústria desce cada vez mais abaixo das condições de existência sua própria classe. Cai no pauperismo que cresce ainda mais rapidamente do que a população e a riqueza. Torna-se, então, evidente que a burguesia é incapaz de continuar sendo a classe dominante da sociedade, impondo como lei suprema suas próprias condições de existência. É incapaz de exercer seu domínio porque não pode mais assegurar a existência de seu escravo em sua escravidão, porque é obrigada a deixá-lo cair num estado tal que deve nutri-lo em lugar de se fazer nutrir por ele (MARX, 2013, p. 37).

Vejamos que nessa citação Marx (2013) argumenta que os trabalhadores descem cada vez mais abaixo das condições de existência de sua própria classe, e, ao mesmo tempo que produzem riquezas, vivem em um pauperismo crescente. Defende que a burguesia não pode ser a classe dominante por não conseguir oferecer o acesso às necessidades básicas de seus trabalhadores.

Ora, olhando a população em situação de rua como integrante da classe trabalhadora, isso fica perceptível. O capitalismo chegou a um ponto no qual parte daqueles inseridos no trabalho informal em sua esfera mais precarizada vive em condições desumanas, e a renda conseguida é suficiente somente para reproduzir a precária sobrevivência em situação de rua. Falar de classe trabalhadora nos remete à consciência de classe. Esse é o tema do último ponto de discussão, que segue. 


\section{Consciência de classe}

Quanto maior for o desenvolvimento das forças produtivas, maior será o papel da consciência. A consciência, ao mesmo tempo que pode contribuir para a existência de uma vida alienada, pode viabilizar a superação da alienação. Seguindo o referencial materialista histórico dialético, que busca uma visão de totalidade e trabalha partindo da existência de uma gama diversa de contradições, consciência e classe precisam ser vistas em conjunto para que haja entendimento sobre suas determinações. Classes e consciência de classe precisam "ser entendidas como partes integrantes de um conjunto dinâmico de fatores sócio-históricos” (MESZÁROS, 2015, p. 61).

Propriedade privada e proletariado são vistos como antítese por Marx e Engels (2011). A primeira se autossatisfaz (lado positivo) e a segunda precisa suprassumir a si mesmo e, por consequência, a propriedade privada (lado negativo). É a propriedade privada que torna os homens detentores somente de sua força de trabalho como proletários. Vemos aqui dois grupos diametralmente opostos: proprietários privados, que visam à conservação, e proletários, que visam à destruição.

[...] nas condições de vida do proletariado estão resumidas as condições de vida da sociedade de hoje, agudizadas do modo mais desumano; porque o homem se perdeu a si mesmo no proletariado, mas ao mesmo tempo ganhou com isso não apenas a consciência teórica dessa perda, como também, sob a ação de uma penúria absolutamente imperiosa - a expressão prática da necessidade -, que já não pode mais ser evitada nem embelezada (MARX; ENGELS, 2011, p. 49, grifo nosso).

O proletariado atinge a consciência necessária - verdadeira - quando toma consciência de seu encargo na história. A consciência contingente refere-se a proletários ou o proletariado de forma geral que percebe uma meta. Vincula-se a uma consciência de grupo que pode não perceber o todo, mas a parte.

“A consciência de classe necessária é a do caráter necessariamente global de qualquer alternativa histórica viável em relação à ordem das relações produtivas vigentes" (MESZÁROS, 2008, p. 89). A consciência necessária busca a totalidade, vê o âmago das contradições, ainda que tenha objetivos que pareçam limitados. Percebe a necessidade de pensar no todo e de que forma as ações imediatas influenciarão o todo e o objetivo máximo que se deseja alcançar. A contingente entende somente as partes, fica nas contradições aparentes, envolve-se em conflitos locais e busca a resolução sem pensar em alternativas mais abrangentes.

A consciência de classe proletária é, portanto, a consciência do trabalhador de seu ser social como ser enquistado no antagonismo estrutural necessário da sociedade capitalista em oposição à contingência de grupo, que percebe somente uma parte mais ou menos limitada da confrontação global (MESZÁROS, 2008, p. 72).

Meszáros (2008, p. 66) aponta que surgiram diversas teorias que visavam esconder as contradições inerentes ao capitalismo com a troca de palavras como classes sociais, capitalismo, burguesia, proletariado, pois representavam algo "ideologicamente tendencioso". A defesa de tais teorias em prol de uma suposta neutralidade axiológica significava o suposto fim da ideologia. Entre os termos utilizados, destacamos sociedade industrial, "grupos de renda mais baixa e alta" (MESZÁROS, 2008, p. 66).

A teoria marxista aponta uma separação ineliminável entre capital e trabalho, consequência da estrutura da sociedade capitalista que promove acumulação de riquezas e acumulação de 
miséria, sendo que quanto maior a miséria de muitos, maior a riqueza de poucos. Ainda que os trabalhadores consigam salários que remunerem acima do valor de sua força de trabalho, persistirá tal relação antagônica entre capital e trabalho enquanto o modo de produção capitalista existir. Trata-se de uma "subordinação estrutural necessária do trabalho ao capital na sociedade de mercadorias” (MESZÁROS, 2008, p. 68).

Vejamos que os interesses entre dominantes (burguesia) e subordinados (proletariado) é substancial. Enquanto os dominantes aceitam alterações e reformas dentro da ordem que não possuem o poder de retirar-lhes a dominação, isso é prejudicial aos subordinados, visto que permanecerão dessa forma. Os primeiros visam preservar sua posição, conservando a sociedade capitalista; já os segundos precisam romper com tal sociedade para poderem se libertar da subordinação.

Para Meszáros (2008), enquanto os integrantes da classe dominante buscam individualmente seus interesses, de forma que, mesmo quando se unem, o objetivo é que prevaleçam seus interesses privados, a classe subordinada, ainda que possua individualmente e como classe interesses específicos, “ 'a curto prazo' [...] em um momento dado, podem estar em oposição radical ao interesse de mudança estrutural a 'longo prazo' “(MESZÁROS, 2008, p. 70).

A consciência de classe é um processo de formação. Ocorre de forma dialética, e não de uma hora para outra, nem de maneira espontânea. A organização política é fundamental para a sua concretização. Lembramos que, no âmbito da expressão da questão social discutida neste artigo, o movimento nacional da população em situação de rua é fundamental para esse processo.

Quando se caracteriza meramente como uma classe contra o capital, é uma classe em si, e no momento em que alcança a consciência de classe, o proletariado forma-se como uma classe para si.

O conceito de proletariado também como uma classe para si implica uma universalidade autoconstituinte, isto é, uma oposição consciente não somente à particularidade burguesa, mas a qualquer particularidade, inclusive aquela que acompanha necessariamente todas as formas do "poder político propriamente dito", mesmo se este estiver nas mãos do proletariado (MESZÁROS, 2008, p. 77).

Assim, o proletariado é uma classe em si perante o capital; e torna-se uma classe para si quando percebe a necessidade da destruição da divisão da sociedade de classes. Somente dessa forma pode romper com a subordinação aos dominantes, inerente ao capitalismo. A consciência de classe para si abarca uma consciência necessária de destruição do que existe para que a reconstrução não mais tenha como norte a exploração.

Nesse contexto, a burguesia nunca poderá tornar-se uma classe para si, pois seu objetivo é perpetuar a sua dominação. Para isso, a existência da propriedade privada e do proletariado é imprescindível. Ao contrário do proletariado, que precisa suprassumir-se, e com isso destruirá junto com a própria condição de submissão a dominação e a propriedade privada.

Para a elevação do proletariado e da consciência de classe em si rumo à consciência de classe para si, é indispensável a organização política. Porém o reconhecimento de sua importância não significa sua determinação de diferenciação entre classe em si e para si, visto que a elevação em prol da classe para si é mais complexa, e, se bastasse a organização política para a classe tomar a consciência para si, a burguesia também poderia chegar a esse momento de consciência. Todavia, conforme discutimos, a consciência de classe para si envolve o reconhecimento da necessidade de destruição da exploração presente na divisão da sociedade capitalista em classes, e não a conservação defendida pelos burgueses, e a formação da consciência de classe possui terreno na história. É uma construção histórica (MESZÁROS, 2008). 


\section{Considerações finais}

Ao longo do artigo, refletimos sobre algumas perguntas. Agora sintetizaremos nossas considerações sobre o que pensamos.

A população em situação de rua é um grupo marcado pela heterogeneidade. São, em sua maioria, trabalhadores desempregados que sobrevivem nas ruas primordialmente pelo trabalho informal. Eles não escolheram viver nas ruas, porém, sem alternativas, acabaram nesta situação: vivendo na rua e da rua.

A classe trabalhadora seria formada somente pelos operários que produzem a riqueza material ou seriam todos aqueles que vivem do trabalho e que a única mercadoria que possuem para trocar no mercado de coisas é a sua força de trabalho? Entendemos a classe trabalhadora de forma ampliada, composta de todos aqueles que possuem como única mercadoria a sua força de trabalho.

A superpopulação relativa, aquela que não compõe o exército ativo ou o faz de forma irregular, composta das três formas básicas e o lumpemproletariado, é parte da classe trabalhadora, inclusive a população em situação de rua, que pode estar em cada uma das formas básicas da superpopulação relativa, com ênfase na forma estagnada, visto que os dados das pesquisas evidenciam seu vínculo com o trabalho informal.

Assim, todos aqueles que só possuem a força de trabalho para trocar no mercado de coisas compõem a classe trabalhadora, sejam eles do exército ativo, sejam da superpopulação relativa. É prejudicial restringir aos que criam diretamente mais-valia, os trabalhadores do chão de fábrica. Por isso, reiteramos que defendemos a classe trabalhadora ampliada, e a população em situação de rua, como superpopulação relativa, faz parte dela.

O último ponto que destacamos é a consciência de classe, necessária para reconhecer a estrutura desse modo de produção como produtora da questão social, com todas as suas expressões, e perceber a necessidade de criar outra sociedade, com um modo de produção no qual não exista exploração de nenhum tipo. Lembramos que o movimento nacional da população em situação de rua é muito importante para contribuir com a aproximação da consciência de classe para si.

Portanto, percebemos a população em situação de rua como parte da superpopulação relativa, em cada uma de suas formas, e, como tal, compõe a classe trabalhadora, que possui somente a sua força de trabalho para trocar no mercado de coisas, sendo representante da "acumulação" de miséria presente em meio à acumulação de riqueza produzida no capitalismo, fundamental como superpopulação relativa para esse modo de produção. Um produto necessário que atua como alavanca ao processo produtivo. A supressão do capitalismo, com o desenvolvimento de outro modo de produção, é o caminho para a superação das contradições que lhe são inerentes.

\section{Referências}

ALVES, Maria Aparecida; TAVARES, Maria Augusta. A dupla face da informalidade do trabalho "autonomia" ou "precarização". In: ANTUNES, Ricardo (org.). Riqueza e miséria do trabalho no Brasil. São Paulo: Boitempo Editorial, 2006. p. 425-444.

ANTUNES, Ricardo. Afinal, quem é a classe trabalhadora? Revista de Estudos do Trabalho, n. 3, p.1-9, 2008. 
BEZERRA, Juscelino Eudâmidas. Perspectivas teóricas nos estudos da classe trabalhadora: apontamentos e reflexões. Revista Pegada, v. 14, n. 1, p. 39-57, jul. 2013.

BORIN, Marisa do Espírito Santo. Os moradores de rua em São Paulo e suas relações com o mundo do trabalho. Cadernos Metrópole, n. 12, p. 49-64, jul. 2004.

BRASIL. Sumário executivo da Pesquisa Nacional sobre a população em situação de rua. Ministério de desenvolvimento social e combate à fome, Brasília, abril de 2008.

CHILE. En Chile Todos Contamos: Segundo cadastro Nacional de Personas en situación de calle. Ministerio de Desarrollo Social. 2012.

ESCOREL, Sarah. Vidas ao léu: trajetória de exclusão social. Rio de Janeiro: Fiocruz, 1999.

GIORGETTI, Camila. Moradores de rua: Uma questão social? São Paulo: Fapesp, 2006.

IBGE, Instituto Brasileiro de Geografia e Estatística. Comissão nacional de Classificação.

Disponível em: https://cnae.ibge.gov.br/en/component/content/article/97-7a12/7a12-voce-sabia/

curiosidades/1617-brasil-tem-mais-mulheres.html. Acesso em: 11 ago. 2020.

IBGE, Instituto Brasileiro de Geografia e Estatística. Indicadores Sociodemográficos: Prospectivos para o Brasil 1991-2030. Rio de Janeiro: Arbeit, 2006.

KUNZ, Gilderlândia da Silva. Os modos de vida da população em situação de rua: narrativas de andanças nas ruas de Vitória. 2012. Dissertação (Mestrado em Psicologia Social) - Universidade Federal do Espírito Santo, 2012.

LESSA, Sérgio. Marx, Lukács, trabalhadores e proletariado. Disponível em: http://www.sergiolessa. com/CapLivro08/mrx_lkcs_classes_2008.pdf. Acesso em: 5 nov. 2015.

LINDEN, Marcel Van der. Rumo a uma nova conceituação histórica da classe trabalhadora. Revista História, v. 24, n.2, São Paulo, p. 11-40, 2005.

MARINI, Ruy Mauro. El concepto de trabajo productivo. Disponível em: http://www.marini-escritos. unam.mx/078_trabajo_productivo.html. Acesso em: 26 out. 2015.

MARX, Karl. O Capital: Crítica da economia política - Livro I: o processo de produção do capital. 1. ed. São Paulo: Boitempo, 2013.

MARX, Karl; ENGELS, Friedrich. Manifesto comunista. [S.l.]: Instituto José Luis e Rosa Sundermann, 2003.

MESZÁROS, Istvan. Filosofia, ideologia e ciência social. São Paulo: Editora Boitempo, 2008.

NETTO, José Paulo. A Questão Social na América Latina. In: GARCIA, Maria Lúcia Teixeira; RAIZER Eugênia Célia (org). A questão social e as políticas sociais no contexto latino-americano. Vitória: Edufes, 2013.

PAMPLONA, João Batista. Erguendo-se pelos próprios cabelos: auto-emprego e re-estruturação produtiva no Brasil. São Paulo: Germinal, 2001.

PAMLONA, João Batista et al. 0 setor informal. São Paulo: Educ, 2001.

PEREIRA, Camila Potyara. Rua sem saída: Um estudo sobre a relação entre o Estado e a População de Rua de Brasília. 2008. Dissertação (Mestrado em Serviço Social) - Universidade de Brasília, 2008.

PRANDI, José Reginaldo. 0 trabalhador por conta própria sob o capital. São Paulo: Símbolo, 1978. 
PRATES, Jane Cruz; PRATES, Flávio Cruz; MACHADO, Simone. Populações em situação de rua: os processos de exclusão e inclusão precária vivenciados por esse segmento. Revista Temporallis, ano 11, n. 22, Brasília/DF, p. 191-215, jul./dez. 2011.

ROSA, Maria Moreno Maffei. Vidas de Rua. São Paulo: Hucitec/Associação Rede Rua, 2005.

SILVA, Maria Lúcia Lopes. Trabalho e população em situação de rua no Brasil. São Paulo: Cortez, 2009.

SNOW, David; ANDERSON, Leon. Desafortunados: um estudo sobre o povo da rua. Petrópolis: Vozes, 1998.

SOARES, Marcos Antonio Tavares. Trabalho Informal: da funcionalidade à subsunção ao Capital. Vitória da Conquista: Edições Uesb, 2008.

VALÊNCIA, Adrián Sótelo. Trabalho, classe trabalhadora e proletariado ensaio sobre as contradições e crises do capitalismo contemporâneo. Revista HISTEDBR On-line, n. Especial, Campinas, p. 3-15, maio 2009.

TAVARES, Maria Augusta. Trabalho informal: os fios (in)visíveis da produção capitalista. Revista Outubro, n. 7, p. 49-60, 2002.

TIENE, Izalene. Mulher moradora na rua: entre vivências e políticas sociais. Campinas, São Paulo: Editora Alínea, 2004.

THOMAZ JÚNIOR, Antônio. Um olhar auto-crítico do trabalho e da classe trabalhadora no Brasil do século XXI. Anuário da faculdade de geografia e história da Universidade das Palmas de Gran Canária. Vegueta, número 10, 2008.

TIENGO, Verônica Martins. Alterações nas expressões da questão social da população em situação de rua. Revista Lutas Sociais, v. 22, n. 41, p. 361-372, jul./dez. 2018a.

TIENGO, Verônica Martins. O fenômeno população em situação de rua enquanto fruto do capitalismo. Revista Textos \& Contextos, v. 17, n. 1, p. 138-150, jan./jul. 2018b.

TIENGO, Verônica Martins. Rualização e informalidade: frutos do capitalismo. Curitiba: Editora Appris, 2020.

VARANDA, Walter; ADORNO, Rubens de Camargo Ferreira. Descartáveis urbanos: discutindo a complexidade da população de rua e o desafio para políticas de saúde. Revista Saúde e Sociedade v.13, n. 1, p. 56-69, jan./abr. 2004.

VIEIRA, Maria Antonieta; BEZERRA, Eneida Maria Ramos; ROSA, Cleisa Moreno Maffei. População de rua: Quem é, Como vive, Como é vista. 3. ed. São Paulo: Hucitec, 2004. 